\title{
Remote analogical reminding
}

\author{
CHARLES M. WHARTON, KEITH J. HOLYOAK, and TRENT E. LANGE \\ University of Califormia, Los Angeles, Califormia
}

\begin{abstract}
Remote analogical reminding is hypothesized to occur when one episode is cued by another sharing similar themes but not similar object, character, or event descriptions. We report three experiments exploring this view. Subjects' remindings in Experiment 1 showed sensitivity to remote analogical similarity even though targets were encoded only briefly in an incidental learning paradigm. Experiment 2 subjects showed reliable remindings of remote analogs with study-test delays of up to 1 week. Experiment 3 demonstrated that remote analogical reminding effects are not an artifact of subjects' editing nonanalogical remindings. All experiments supported the hypothesis that human memory is sensitive to remote analogical similarity. We discuss the implications of these findings for memory models. Future progress requires the development of formal models that quantify factors relevant to reminding performance, such as reminding interference, transfer-appropriate processing, and domain expertise.
\end{abstract}

Intelligent access to knowledge in long-term memory, for people or computers, can depend on sensitivity to similarity solely at the level of inferred plans, goals, solutions, or themes (Clement, 1988, 1991; Holyoak \& Thagard, 1995; Poze, 1983; Schank, 1982; though see Dunbar, 1995; Perkins, 1983; Weisberg, 1993). For example, a ready explanation for a friend's claim of not really wanting a particular job after being turned down for it may be found by recalling Aesop's fable of the fox and the unreachable "sour" grapes. Here, an episode in memory is cued by a current episode sharing little or no similarity at the level of surface features (i.e., similar concepts that are explicitly described and hence do not have to be inferred). The cue and the retrieved target have few objects, characters, or social situations in common. However, the sour grapes and the disgruntled job-seeker stories are similar because they are analogous: There is a systematic correspondence between the actors, actions, plans, and goals of both stories. This type of retrieval is guided solely by analogical similarity and can occur in situations ranging from idle thought to focused argument and problem solving. We refer to this phenomenon as remote analogical reminding (Gentner, 1983; Gick \& Holyoak, 1980; Keane, 1985). ${ }^{1}$

This paper is based on a PhD dissertation submitted to the University of California, Los Angeles, by C.M.W. Preparation of this article was supported by National Science Foundation Grant SBR-9310614. We thank Michael $\mathrm{C}$. Anderson for suggesting the use of a forcedreminding condition. We also benefited from comments by Art Markman, Barry Stein, and Robert Weisberg, as well as from comments from several anonymous reviewers. Ari Schindler demonstrated superb skill in creating the computer programs used to generate the materials in these experiments. Assistance in data collection and analysis was provided by Autumn Bryant, Jerico Mangalindan, Sheila Tejada, Michelle Voss, and Jenny Wong. These experiments were reported at the 34th Annual Meeting of the Psychonomic Society, Washington, DC, November 1993. T.E.L. is in the Department of Computer Science at UCLA. Correspondence should be addressed to $\mathrm{C}$. M. Wharton, NIH/NINDS $\mathrm{MNB} / \mathrm{CNS}$, Building 10, Room 5s209, 10 Center Drive MSC 1440 , Bethesda, MD 20892-1440 (e-mail: wharton@codon.nih.gov).
There currently is no consensus as to whether in fact memory is sensitive to remote analogical similarity. At one extreme, Gentner, Rattermann, and Forbus (1993, pp. 527-528) and Reeves and Weisberg (1994, p. 395) have argued that memory access is guided largely by surface cues, with only a small part being played by analogical similarity. In this view, human sensitivity to analogical similarity arises primarily at the stage of analogical mapping, which is subsequent to the retrieval process. At the other extreme, in artificial intelligence models of casebased reasoning it is generally assumed that human memory retrieval is routinely guided by similarities at the level of goals and plans (e.g., Hammond, 1989; Kolodner, 1993). The view that analogical similarity influences memory retrieval is supported by various studies (e.g., Holyoak \& Koh, 1987; Johnson \& Seifert, 1992; Read \& Cesa, 1991; Wharton et al., 1994). However, it has yet to be convincingly shown that analogical similarity influences retrieval when cues and targets share little or no surface overlap or descriptions of similar social events.

Our goal in the present study was to assess whether remote analogical remindings can be consistently observed in a controlled laboratory study using complex story materials. After discussing similarity taxonomies and empirical findings relevant to the question of remote analogical reminding, we will present three experiments. The results of these experiments indicate that subjects' remindings are indeed influenced by remote analogical similarity. Finally, we will discuss the implications of these results for models of memory and problem solving.

\section{Levels of Similarity}

Before further discussion, it will be useful to consider taxonomies of similarity at different levels of abstraction. On the basis of empirical investigations of discourse comprehension, one can distinguish similarity for narrative episodes at (at least) the levels of objects, social and physical situations, and themes. Object similarity is based on similar objects or characters (e.g., a story about a fox is 
similar to a story about a wolf). Situational similarity refers to scripts that involve similar personal roles, action sequences, and social situations (e.g., trying out for a band is similar to interviewing for a job) (see Abbot, Black, \& Smith, 1985; Cantor, Mischel, \& Schwartz, 1982; Rifkin, 1985; Schank, 1982). Relative to situational similarity, thematic similarity is based on more abstract correspondences of plans, goals, and plan failures (e.g., the theme of the sour grapes fable is similar to the theme of the anecdote about the disgruntled job seeker) (see Dyer, 1983; Schank, 1982). Two representations can share similarity at any or all levels.

Whereas work in text comprehension has tended to produce taxonomies of similarity tied specifically to the content of narratives, theorists in the area of analogical problem solving have discussed more content-independent taxonomies. A number of proposals have involved variants of a three-level taxonomy based on the predicateargument structure of propositions (Gentner, 1983, 1989; Halford, 1992; Halford \& Wilson, 1980; Holyoak \& Thagard, 1989; Premack, 1983). For example, Gentner has distinguished similarity at the levels of attributes (one-place predicates), first-order relations (multi-place predicates with objects as arguments), and higher order relations (multi-place predicates with at least one propositional argument). The similarity of a fox to a wolf is based in part on their shared categorization as animals, where animal can be represented as an attribute. The similarity of the event of a boy reaching for cookies to the event of the fox reaching for grapes is based on the first-order relation reach. And finally, the similarity of the two sourgrapes analogs to each other depends on such higher order relations as cause, represented as a relation between propositions describing events. With respect to narratives, similarities based on attributes, first-order relations, and higher order relations correspond in an approximate (but imperfect) manner to similarities of objects, situations, and themes, respectively.

For present purposes, we will refer to the tripartite division into object, situational, and thematic similarity. In general terms, in the present experiments we investigate reminding between stories in which object similarity is kept uniformly low, and situational similarity and thematic similarity are varied factorially.

\section{Empirical Investigations of \\ Remote Analogical Reminding}

Our focus is explicitly not on the role of remote analogical similarity in problem solving, but rather on whether or not it can be shown that human memory is sensitive to remote analogical similarity. Extrapolating evidence for this question from studies of analogical problem solving requires consideration of a number of issues outside the scope and the intent of the experiments presented here. Accordingly, we have restricted our literature review to directed reminding studies. These studies have provided tentative evidence that remote analogical similarity influences memory retrieval.
In the directed reminding paradigm, subjects are typically given 10 or more brief stories during an encoding session. After a delay (typically between $5 \mathrm{~min}$ and 2 weeks), subjects are provided with new stories as cues. The cues vary in their overlap with the studied stories. Subjects are instructed to read each cue story and then to describe previously studied stories of which they are reminded. The effect of analogical similarity is assessed by comparing the retrieval frequency of stories that are analogous to the cue to the retrieval frequency of comparison stories that are not analogous to the cue. Crucially, each comparison target is constructed by altering the overall sequence of inferred goals and plans in an analog target to make a narrative with a different (though related) theme (see Gentner et al., 1993; Read, Druian, \& Miller, 1989; Wharton et al., 1994).2 Also, each related comparison target and analog target are constructed so that they both share the same degree of object and situational overlap with their common cue.

To make clear how comparison stories are related to analog stories, Table 1 shows an example of the materials used in the present experiments. Stories in each column are based on the same basic theme; accordingly, a cue and a target from the same column are analogs. For example, the stories in the left column all instantiate some form of "sour grapes"- the main characters fail to attain some goal and then try to make that failure seem less important by disparaging that goal. The stories in the right column instantiate a different theme, "selfblame" - the main characters also fail to attain some goal, but they blame their failure on a personal shortcoming.

A cue story and a target story drawn from different columns are comparison stories that we refer to as disanalogs. Disanalogs describe different but related themes. For example, the target story about "John" (Theme 1) and the close cue story about "Jennifer" (Theme 2) both describe characters who fail to achieve a goal; however, the failure attributions are different.

Although previous directed reminding studies have generally shown that subjects are more frequently reminded of analogs than of disanalogs, this difference has not always been statistically reliable (Gentner et al., 1993; Hammond, Seifert, \& Gray, 1991). Wharton et al. (1994) argued that the failure of previous studies to find significant differences between analog and disanalog reminding could be a function of experimental design. The left side of Figure 1 illustrates the type of single-target design used by Gentner et al. and Hammond et al. Here, each cue (bottom row) is thematically related to only one target (top row), either an analog or a disanalog. The right side of Figure 1 depicts the double-target design introduced by Wharton et al. ${ }^{3}$ Here, each cue is an analog of one target and a disanalog of the other target.

In a single-target design, the reminding frequencies of analogs and disanalogs are assessed in separate conditions, in which either the analog or the disanalog (whichever was presented) will be the item in memory most similar to the cue. (Recall that analog story pairs and disanalog 
Table 1

Example of Stories in the Close Condition and in the Remote Condition

\section{Theme 1: Sour Grapes}

Target: John was very confident about himself. He did a lot of homework in order to get good marks. John had only a B + GPA in his first year in high school. He was sure he could do better. Earlier, a counselor had arranged for him to meet with the recruiter from Yale. When he got home from class, he opened the thin rejection letter from Yale. That night he mentioned to his father how he believed that people from Ivy League schools were pretentious.

Close Cue: Lisa spent long hours trying to make her corporation successful. She was very sure about herself. Lisa had broken up with her fiance a year ago. She wanted to meet someone new. A co-worker set her up to go out with someone he knew well. She waited at the fancy restaurant until 8:30 and then left without ordering dinner. She told her friend that she thought that her date probably wasn't that handsome and that investment bankers are really boring, anyway.

Remote Cue: Elle was a unicorn who wanted to see what was on the other side of the river. She thought the lands over there were enchanted and rich with meadows and fruit trees. One day she set out to cross the river. Unfortunately, the water was very fast and too deep. Elle swam as hard as she could but after 20 minutes she had to turn back because of fatigue. Elle decided that the stories about the land on the other side of river were just false rumors and that there was probably nothing of worth over there.

\section{Theme 2: Self-Blame}

Target: Derrick had failed to make the gymnastics team last fall. He practiced a lot in order to make the team. He wanted to try again. Derrick was positive he had a lot of potential. His PE teacher had gotten him a tryout with the gymnastics team coach. The gymnastics team coach watched him perform and then told his PE teacher that he didn't want him on the team. Derrick confessed to his teacher that the coach undoubtedly thought he, Derrick, didn't have the talent for gymnastics.

Close Cue: Jennifer worked hard attempting to create a new business venture. She had divorced her husband some time before. She wanted to start socializing again. A friend fixed a blind date for her with one of his friends, Henry, from work. Jennifer was very excited. She waited alone at the entrance of the museum for 2 hours. She confessed to her friend that her date thought she wasn't that attractive and that software engineers aren't interesting.

Remote Cue: Jane was a unicorn who wanted to see what was on the other side of the river. She thought the lands over there were enchanted and rich with meadows and fruit trees. One day she set out to cross the river. Unfortunately, the water was very fast and too deep. Jane swam as hard as she could but after 20 minutes she had to turn back, exhausted. Jane decided that she wasn't worthy of being in the magic lands. story pairs are equally similar at the level of objects and situations and that disanalog story pairs are moderately related at the level of themes.) In a double-target design, the reminding frequencies of both analogs and disanalogs are assessed in the same condition. Relative to the cue, the analog target will be more similar than the disanalog target, so analogs will tend to be retrieved more frequently than disanalogs. Consequently, the relative reminding frequency of analogs as compared with that of disanalogs will tend to be higher in double-target than in single-target designs. The results of Wharton et al. (1994) supported this hypothesis. These authors used a design in which all subjects saw stories in both single-target and double-target conditions. In three of four experiments, the difference in reminding between analogs and disanalogs was greater in the double-target condition than in the single-target condition (across experiments, $24 \%$ and $12 \%$, respectively). Wharton et al. found consistent significant differences between analog reminding and disanalog reminding only in the double-target condition. ${ }^{4}$

The present study extends Wharton et al. (1994) in the following ways. First, Wharton et al.'s analog cues and

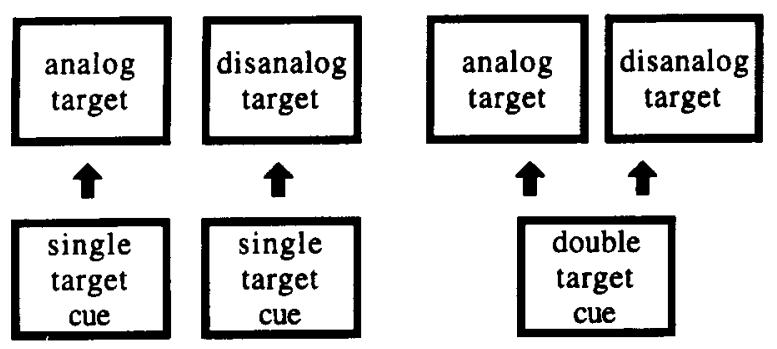

Figure 1. Single-target and double-target designs. targets shared similarity at the level of objects and situations. Remote analogical reminding was not tested. Accordingly, subjects in all of the present experiments were given remote analogs as reminding cues. Second, Wharton et al. used only a 5-min delay between the initial study session and the presentation of the reminding cues. To explore whether remote analogical similarity influences memory retrieval across longer temporal intervals, in Experiment 2 of the present study we used 5-min, 24-h, and 7-day delays between study and test. Finally, although Wharton et al. used instructions that encouraged subjects to provide multiple remindings if a cue triggered retrieval of more than one target, subjects may have surreptitiously edited their remindings, preferring to report analogs rather than disanalogs. The results of Wharton et al. may be due only to the effect of analogical similarity on postaccess editing. Thus, in Experiment 3 of the present study we used instructions designed to test whether subjects edit nonanalogical remindings.

\section{Materials Overview}

The experimental factors necessary for exploring remote analogical reminding were manipulated by way of the configurations of target stories and cue stories presented to subjects. In this section, we discuss further details of how we produced target-cue configurations. In addition to varying analogical similarity with our materials, we also manipulated the degree to which cues and targets shared situational similarity. As shown in Table 1, each theme (here "sour grapes" and "self-blame") is instantiated by one target story and two cue stories. (Two additional sets of materials are shown in the Appendix.)

The cue stories differ in terms of the relative similarity of their situational descriptions to those in the target. Re- 
mote cues and targets minimize similarity at both the object and situation levels (e.g., a student applying for college vs. a unicorn attempting to cross a river). In contrast, close cues and targets share some inferred situational overlap (e.g., a teacher arranging a gymnastics team tryout for a student matched to an adult arranging a blind date for a friend).

The same set of basic situations and events was used to construct each of the targets and close cues. However, story characters that play corresponding thematic roles are themselves relatively dissimilar (e.g., a gymnast and a software engineer). Thus, close story pairs of cues and targets do not share any similarities at the level of objects.

Crossing thematic similarity and situational similarity produces four conditions (Table 2). In addition to these four conditions, the experimental design included a close unrelated condition (targets and close cues each from different materials groups) and a remote unrelated condition (targets and remote cues each from different materials groups). (Table 1 displays only 1 of the 14 materials sets.) Because the two themes within a set are partially related on the level of plans and goals, disanalog cues are more similar than unrelated cues to the target.

In all experiments, all 28 target stories and 56 cue stories appeared in analog, disanalog, and unrelated pairings. Thus, what was particular to each condition was not the stories themselves, but rather the relationship between pairs of stories.

To show that our manipulations of thematic similarity and situational similarity are psychologically meaningful, we had 84 subjects rate the similarity (range: $1=$ completely dissimilar; $10=$ completely identical) of story pairs from each of the six conditions described above.

\section{Results and Discussion}

To enable simultaneous generalization over both subjects and stories, the analysis of variance (ANOVA) tests reported in the present experiments used the $\min F^{\prime}$ statistic (Clark, 1973; Wickens \& Keppel, 1983). Each min $F^{\prime}$ analysis was computed from a subject ANOVA and a story ANOVA. Cue-target configuration ( 1 to $n$ ) was an additional fixed variable in each subject ANOVA performed for the similarity ratings and for Experiment 1 .

We used two criteria for rejecting the null hypothesis. The strict criterion required the difference between conditions to be significant by a $\min F^{\prime}$ analysis. The lenient criterion required (1) the difference between conditions to be marginally significant by $\min F^{\prime}$ or significant by both subject ANOVA $\left(F_{1}\right)$ and by story ANOVA $\left(F_{2}\right)$, and (2) the difference between conditions to have been predicted beforehand. A result based on the lenient cri-

Table 2

Four Conditions Produced by Crossing Thematic Similarity and Situational Similarity

\begin{tabular}{cll}
\hline & \multicolumn{2}{c}{ Thematic Similarity } \\
\cline { 2 - 3 } Situational Similarity & \multicolumn{1}{c}{ High } & \multicolumn{1}{c}{ Moderate } \\
\hline Low & $\begin{array}{l}\text { remote analog } \\
\text { close analog }\end{array}$ & $\begin{array}{l}\text { remote disanalog } \\
\text { close disanalog }\end{array}$ \\
\hline
\end{tabular}

terion will be treated as relatively preliminary unless corroborated by other analyses.

The mean similarity ratings for each of the six conditions are shown in Figure 2. Differences between conditions were tested in a 3 (thematic similarity: analog, disanalog, unrelated story pairs) $\times 2$ (situational similarity: close cue, remote cue) within-subjects/within-stories $\min F^{\prime}$ ANOVA.

The similarity ratings confirm the psychological reality of the variables manipulated in the configurations of target stories and cue stories. The main effects of thematic similarity and situational similarity were both reliable $\left[\min F^{\prime}(2,72)=10.42, p<.001, \min F^{\prime}(1,66)=15.51\right.$, $p<.0001$, respectively]. The main effect of situational similarity does not indicate that close story pairs share more surface features than do remote story pairs. Because the close story pairs were explicitly designed to not share surface features, this effect confirms that subjects infer more similar situations in close cues and targets than in remote cues and targets.

The interaction of thematic similarity and situational similarity was reliable $\left[\min F^{\prime}(2,160)=5.14, p<.01\right]$. This interaction reflected that (1) close analog and disanalog pairs were rated as more similar than were remote analog and disanalog pairs, and (2) close, unrelated pairs were rated approximately as similar as remote, unrelated pairs (because both are functionally remote and unrelated).

\section{EXPERIMENT 1}

Thematic inferences are hypothesized to be part of ordinary discourse comprehension (Graesser, Singer, \& Trabasso, 1994). According to this view, thematically oriented encoding or retrieval procedures (e.g., summarization, problem solving) should not be required to produce remote analogical reminding. To explore this hypothesis, we used encoding procedures and retrieval procedures that appeared not to direct subjects' attention to the theme of cues and targets.

Subjects initially rated the imageability of 12 narrative texts similar to those shown in Table 1. Subjects were not told they would later be asked to recall these stories. After a 5-min filler task, subjects were presented with another set of 10 new stories. These cue stories were analogous, disanalogous, or unrelated to the previously seen targets. All subjects were given an equal number of remote cues and close cues. In the remote condition, as well as in the close condition, we predicted that subjects would be reminded more frequently of analog targets than of disanalog targets.

Wharton et al. (1994) found that the difference between analog reminding and disanalog reminding was generally greater in double-target conditions than in singletarget conditions. To see if this difference would hold with remote analogs, all subjects participated in both singletarget and double-target conditions.

Close cues were given to subjects in order to assess the role of situational similarity in analogical reminding. We predicted that subjects would be reminded more frequently 


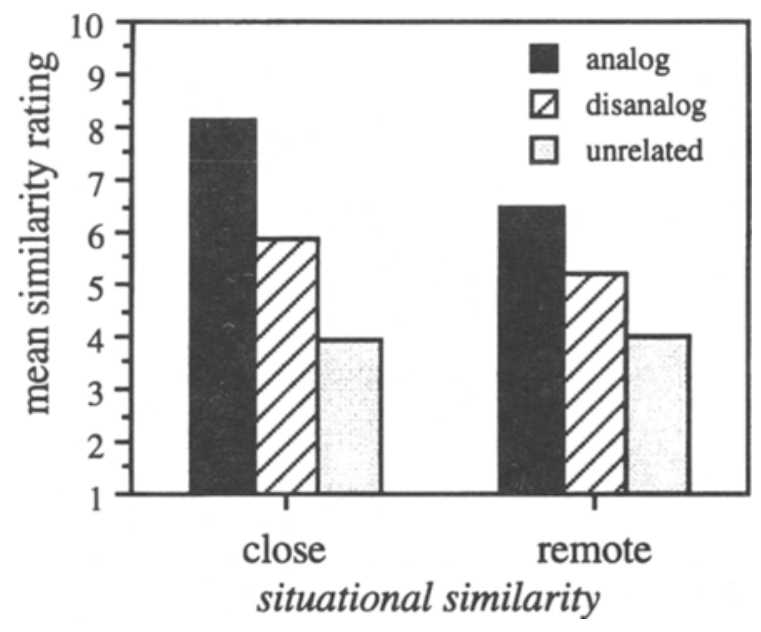

Figure 2. Mean similarity ratings as a function of thematic similarity and situational similarity.

of analog targets and disanalog targets in the close condition than in the remote condition.

\section{Method}

Subjects. Subjects were 84 UCLA undergraduates ( 57 women, 27 men, mean age 19.5 years). All subjects in all experiments described here reported speaking English as their primary language for the past 10 years and participated either for pay or in order to meet a requirement for one of several psychology courses.

Materials. Materials were presented in target booklets and in cue booklets, one story per page, randomly ordered for each subject. Table 3 shows the designs of target booklets and cue booklets. To make these designs clearer to the reader, we include examples that refer to the protagonists displayed in Table 1.

Each page of the target booklets displayed a 6-point Likert scale $(1=l o w ; 6=h i g h)$ for rating the target story's imageability. To ensure that all stories from every theme group appeared in analog, disanalog, and unrelated conditions, a Latin-square design was used to create 28 different groups of cues and targets. These groups appeared in all of the present experiments.

Procedure. All subjects in the present experiments were tested in groups of from 1 to 8 people. Subjects in Experiment 1 were read aloud instructions that the experimenter was creating a computer simulation of how people represented stories as a function of narrative imagery. Subjects were told that in order to provide normative data for the simulation. they would be asked to read and rate a series of stories for imageability (defined as "how easy it is to imag- ine or see in your mind what is occurring in this story"). Subjects were given the target booklets and then told that they would be given $50 \mathrm{sec}$ to read and rate each story. The experimenter signaled subjects when to go on to the next story.

After completion of the ratings, subjects participated in a 5-min filler task. The experimenter then informed the subjects that the computer simulation was also a model of story reminding. Subjects were given the cue booklets. Subjects were to read each story and write down as accurately as possible any of the stories rated earlier of which they were reminded. If a story did not remind them of anything, they were to go on to the next story. Subjects were informed that there was no time limit per story but that once they started reading a new story, they were not to go back to previous stories. The experimental session lasted approximately $30 \mathrm{~min}$.

\section{Results}

The dependent measure of reminding in all experiments was the proportion of possible target stories of each type (analog, disanalog, and unrelated) retrieved for each cue type. For each story written down by a subject, access credit was given to whichever target had the most content words recalled. When a retrieval attempt produced equal numbers of content words from two stories, or when both stories were recalled separately, access credit was given to each. In almost all retrievals, subjects included at least one content word that was literally the same as was seen in some target. Thus, our scoring procedure probably resulted in reminding frequencies that were only slightly lower than would have been found using gist scoring. Additionally, our method is less open to scoring biases than is gist scoring (see Wharton et al., 1994, p. 78).

The results of Experiment 1 support the hypothesis that remote analogical similarity influences memory retrieval. Reminding frequencies for analog targets and for disanalog targets are displayed in Figure 3. Mean differences between conditions were tested in a 2 (thematic similarity: analog target, disanalog target) $\times 2$ (situational similarity: close cue, remote cue) $\times 2$ (target number: single target, double target) within-subjects/within-stories $\min F^{\prime}$ ANOVA.

As can be seen in both panels of Figure 3, the main effect of thematic similarity was reliable $\left[\min F^{\prime}(1,79)=\right.$ $6.84, p<.025]$. A planned comparison showed an effect of thematic similarity in the remote condition $\left[\mathrm{min} F^{\prime}(1,75)\right.$ $=4.66, p<.05]$. Multiple remindings were relatively

Table 3

Design of Target Booklets and Cue Booklets for Experiment 1

\begin{tabular}{lcc}
\multicolumn{1}{c}{ Condition } & \multicolumn{1}{c}{ Target Booklets } & Cue Booklets \\
\hline Remote double target & 2 stories (e.g., John & 1 remote cue (analogous to one target, \\
& and Derrick stories) & disanalogous to the other; e.g., Elle story) \\
Remote analog single target & 1 story (e.g., John story) & 1 remote analog cue (e.g., Elle story) \\
Remote disanalog single target & 1 story (e.g., Derrick story) & 1 remote disanalog cue (e.g., Elle story) \\
Remote unrelated & 2 stories (each from & 2 remote unrelated cues (each from \\
& different sets) & different sets) \\
Close double target & 2 stories (e.g., John & 1 close cue (analogous to one target, \\
& and Derrick stories) & disanalogous to the other; e.g., Lisa story) \\
Close analog single target & 1 story (e.g., John story) & 1 close analog cue (e.g., Lisa story) \\
Close disanalog single target & I story (e.g., Derrick story) & 1 close disanalog cue (e.g., Lisa story) \\
Close unrelated & 2 stories (each from & 2 close unrelated cues (each from different sets) \\
& different sets) & \\
\hline
\end{tabular}




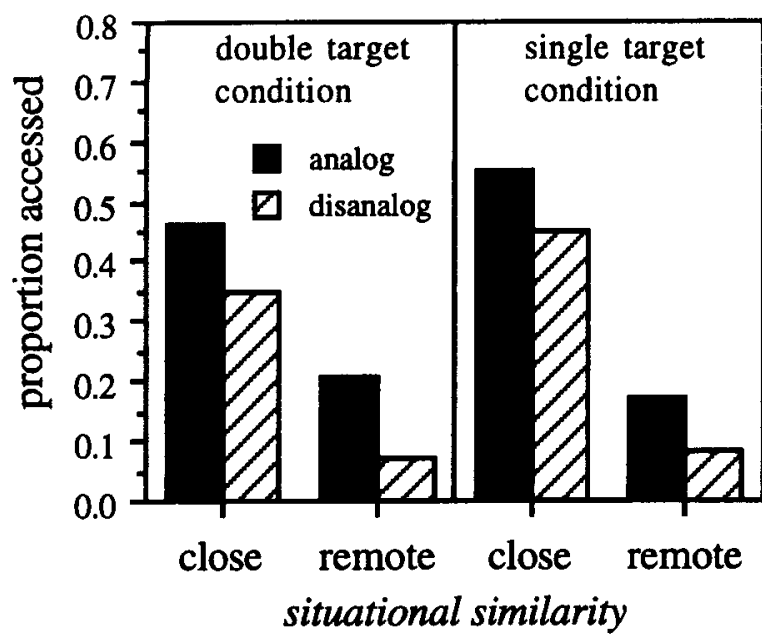

Figure 3. Reminding for target stories in Experiment 1.

rare, with both analog and disanalog targets being retrieved only $8 \%$ of the time in the double-target condition. Subjects retrieved more stories when given close cues than when given remote cues $\left[\min F^{\prime}(1,45)=35.58, p<\right.$ $.0001]$. No other main effects or interactions were reliable (all $\min F^{\prime}<1$ ).

Table 4 shows the frequency of unrelated remindings across all conditions. Because the number of unrelated targets per cue ranges between 10 and 12 , depending upon condition, the frequency of remindings for unrelated targets is not directly comparable with the frequencies for analog conditions and disanalog conditions.

\section{Discussion}

Experiment 1 supports the view that remote analogical similarity influences memory retrieval. Even in the absence of any similarities at the level of objects or situations, subjects were reminded of more analog targets than disanalog targets. This conclusion is particularly supported by the nature of the encoding task: Subjects encoded the targets only by rating them for imageability. Thus, encoding methods oriented toward producing abstract representations are not necessary to produce remote analogical reminding.

In contrast to the results reported in Wharton et al. (1994), the reminding frequency of analogs relative to disanalogs was not greater in the double-target condition than in the single-target condition. The absence of a difference between double-target and single-target conditions may have resulted from chance interactions between specific stories and subjects (e.g., the target analogs in the single-target condition were especially memorable for particular subjects). Regardless, Wharton et al.'s conclusion that a double-target design is more sensitive to analogical reminding effects than a single-target design is only slightly weakened by the results of Experiment 1 . We have conducted five experiments using single-target and double-target designs. Of these experiments, three have shown a greater analogical reminding effect in the double-target condition and two have shown an equal analogical reminding effect between the single-target condition and the double-target condition. No experiment has shown a greater analogical reminding effect in the singletarget condition than in the double-target condition.

Although both thematic similarity and situational similarity influenced reminding, their relative impact differed from that observed in the similarity-rating task. As Figure 2 indicates, remote analog cues and targets (sharing high thematic similarity and low situational similarity) were rated at least as similar to each other as close disanalog pairs (sharing moderate thematic similarity and high situational similarity). However, Figure 3 reveals that in the single-target condition, close disanalog targets were retrieved more than twice as often as remote analog targets. These findings support Gentner et al.'s (1993) conclusion that relational similarity has a greater impact on similarity judgment than on memory retrieval.

\section{EXPERIMENT 2}

In order to examine the effect of remote analogical reminding with relatively long study-test delays, we used three different study-test delays: $5 \mathrm{~min}, 24 \mathrm{~h}$, and 7 days. The frequency of remote remindings after a substantial delay cannot be fairly tested if subjects have not encoded the targets well enough to even remember them. Accordingly, we used two encoding tasks, self-reference orientation and retrieval practice, that have been shown to be effective memory aids (Bellezza \& Hoyt, 1992; Bjork \& Bjork, 1992). In the self-reference orientation task, subjects rated each story for its similarity to their own life experience. In the retrieval-practice task, subjects were given a cued-recall test of the targets immediately after all targets were rated.

To increase the number of observations per condition per subject, we eliminated the single-target condition and the unrelated condition. We predicted findings similar to those of Experiment 1 -an effect of thematic similarity on reminding even with remote cues, and greater reminding for close cues than for remote cues.

\section{Method}

Subjects. Subjects were 84 UCLA undergraduates ( 48 women, 36 men, mean age 18.9 years). Random assignment of subjects to each level of study-test delay proved to be too difficult to undertake because of conflicts imposed by subjects' class schedules. Accordingly, subjects could choose a particular level of time delay.

Materials. The self-reference booklets contained 12 target stories, each displayed on a separate page along with a 10-point Likert scale $(1=$ low; $10=$ high $)$ for rating "How similar is this story

Table 4

Unrelated Target-Reminding Proportions for Experiment 1 as a Function of Cue Type

\begin{tabular}{lcccc}
\hline & \multicolumn{4}{c}{ Cue Type } \\
\cline { 2 - 5 } Situational & Double & $\begin{array}{c}\text { Analog } \\
\text { Single }\end{array}$ & $\begin{array}{c}\text { Disanalog } \\
\text { Single }\end{array}$ & Unrelated \\
Similarity & .15 & .15 & .35 & .38 \\
\hline Close & .21 & .29 & .35 & .27 \\
Remote & & &
\end{tabular}


to experiences you've had in your life?" The retrieval-practice booklets also contained 12 target stories. The bottom portion of each page (except for the first and last pages) displayed the first sentence of a previously rated story and a blank area to write down the rest of the story from memory. The top of each page displayed the entire story that had been cued on the previous page. The reminding booklets contained six cue stories, each displayed on a separate page.

All 28 different cue-target configurations appeared in each of the three levels of study-test delay. The order of target stories in the self-reference booklets and the retrieval-practice booklets was randomly determined for each of the 28 materials groups, with the exception that related target stories were always separated by five other stories. To minimize the possibility that subjects would encode an episodic association between related analog and disanalog target stories, the order of cues in the reminding booklets was random except that unrelated cues appeared in the 1st, 4th, 7th, and 10 th serial positions.

Procedure. Subjects were read aloud instructions that the experimenter was interested in factors involved in remembering stories over a long period of time. Accordingly, subjects would be asked to study some stories about which they would later answer questions. The procedure used with the self-reference booklets was the same as that used during the encoding phase of Experiment 1 (e.g., timed ratings).

After they had rated all of the target stories, subjects were told that they would now practice retrieving the previously rated stories. The booklets in front of them contained the first sentence of one of the previously rated stories. Subjects were to write out from memory everything they could remember about the rest of the story. They were then to turn the page and compare their retrieved story with the story printed there. Subjects took approximately $25 \mathrm{~min}$ in this selfpaced phase of the experiment. After this, subjects in the $24-\mathrm{h}$ and in the 7-day retrieval-delay conditions were asked to return at the appropriate times. Subjects in the 5-min retrieval-delay condition completed a brief filler task. At retrieval, all subjects were given the same instructions as in Experiment 1 . The final reminding phase took approximately $15 \mathrm{~min}$ to complete.

\section{Results}

The results of Experiment 2 demonstrate that subjects' remindings at all levels of delay were influenced by remote analogical similarity. However, the size of this effect appeared to decline as the study-test delay increased. Figure 4 displays reminding frequencies for analog targets and for disanalog targets. Mean retrieval differences between conditions were tested in a 2 (thematic similarity: analog target, disanalog target) $\times 2$ (situational similarity: close cue, remote cue) $\times 3$ (delay: $5 \mathrm{~min}, 24 \mathrm{~h}$, 7 day) mixed-subjects/within-stories min $F^{\prime}$ ANOVA.

Collapsing across retrieval for close cues and remote cues, we found that subjects were reminded of analogs more often than they were reminded of disanalogs [min $\left.F^{\prime}(1,74)=32.65, p<.0001\right]$. Access of both analog and disanalog target stories occurred in $1 \%$ of retrievals in the remote condition and in $6 \%$ of retrievals in the close condition.

The interaction of situational similarity and thematic similarity was significant $\left[\min F^{\prime}(1,50)=4.42, p<.05\right]$. This effect appears to show that the effect of thematic similarity was larger in the close condition than in the remote condition. However, the effect of thematic similarity was reliable in both the remote and the close conditions, respec-

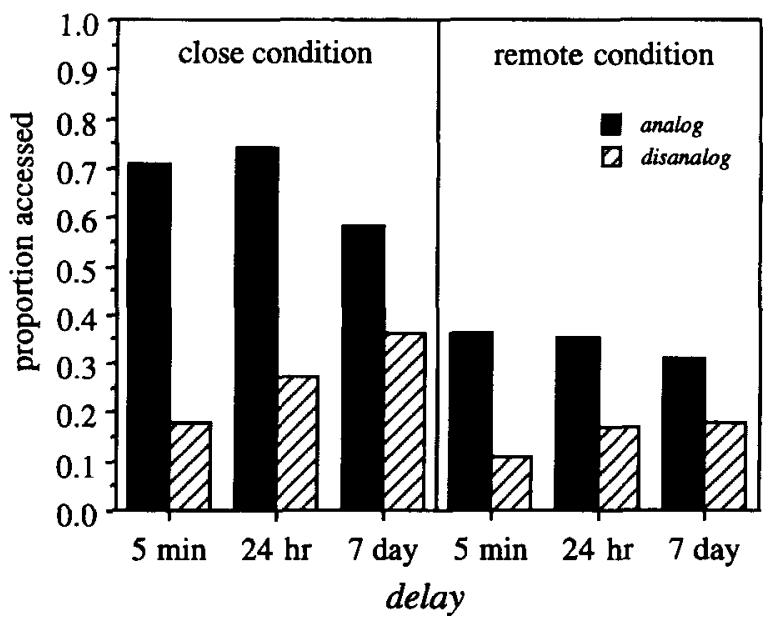

Figure 4. Reminding for target stories in Experiment 2.

tively $\left[\min F^{\prime}(1,108)=6.45, p<.025 ; \min F^{\prime}(1,93)=\right.$ $14.31, p<.001]$.

The main effect of situational similarity was reliable $\left[\min F^{\prime}(1,39)=21.38, p<.0001\right]$. As shown in Figure 4, across all study-test delays, the frequency of subjects' reminding of close analogs was approximately double that of remote analogs.

The absence of a main effect of delay $\left(\min F^{\prime}<1\right)$ indicates that the overall level of reminding did not reliably decrease as the study-test interval increased. However, as shown in Figure 4, the reminding advantage of analog targets over disanalog targets tended to decline (particularly with close cues) as the study-test delay increased. The interaction between delay and thematic similarity was not reliable by $\min F^{\prime}$ analysis but was significant by subject ANOVA and by story ANOVA $\left[F_{1}(2,81)=3.20\right.$, $\left.p<.05 ; F_{2}(2,54)=4.91, p<.025\right]$. In the close condition, the interaction of thematic similarity with delay was not reliable by $\min F^{\prime}$ analysis but was by subject ANOVA and by story ANOVA $\left[F_{1}(1,54)=5.42 ; F_{2}(2,54)=5.00\right.$, both $p \mathrm{~s}<.025]$. In the remote condition, the interaction of thematic similarity with delay was not reliable ( $\mathrm{min}$ $F^{\prime}<1$ ).

Further evidence that remote (and close) analogical similarity influences memory retrieval is provided by separate analyses of each level of delay. The effect of thematic similarity was reliable at the 5-min, 24-h, and 7-day studytest delays, respectively $\left[\min F^{\prime}(1,54)=24.88, p<.0001\right.$; $\min F^{\prime}(1,48)=15.47, p<.001 ; \min F^{\prime}(1,53)=4.22$, $p<.05]$. In the remote condition, the effect of thematic similarity was significant at the 5 -min study-test delay and marginally significant at the 24-h study-test delay, respectively $\left[\min F^{\prime}(1,54)=6.39, p<.025 ; \min F^{\prime}(1,54)=\right.$ $3.39, p<.10]$. At the 7-day study-test delay, the effect of thematic similarity was significant by subject ANOVA and by story ANOVA $\left[F_{1}(1,27)=5.14, p<.05 ; F_{2}(1,27)=\right.$ $5.64, p<.05]$. In the close condition, the effect of thematic similarity was reliable at the 5-min and the $24-\mathrm{h}$ study-test delays, respectively $\left[\min F^{\prime}(1,54)=21.85\right.$, 
$\left.p<.0001 ; \min F^{\prime}(1,52)=12.29, p<.001\right]$. At the 7-day study-test delay, the effect of thematic similarity in the close condition was significant by subject ANOVA and marginally significant by story ANOVA $\left[F_{1}(1,27)=5.60\right.$, $\left.p<.05 ; F_{2}(1,27)=4.14, p<.10\right]$.

The effect of situational similarity was reliable at $5-\mathrm{min}$, 24-h, and 7-day study-test delays, respectively [min $F^{\prime}(1,53)=13.67 ; \min F^{\prime}(1,49)=20.25 ; \min F^{\prime}(1,52)=$ 13.03; all at least $p<.001]$. The interaction of situational similarity and thematic similarity was marginally significant at the 5-min and 24-h study-test delays, but not significant at the 7-day study-test delay, respectively [min $F^{\prime}(1,54)=3.89, p<.10 ; \min F^{\prime}(1,54)=3.00, p<.10$; $\left.\min F^{\prime}<1\right]$.

Table 5 displays the proportion of reminding proportions for unrelated targets.

\section{Discussion}

Taken together, our analyses support the view that remote (and close) analogical similarity influences reminding even with study-test delays of up to 7 days. However, even though there was no reliable overall decline in total story reminding, the effect of thematic similarity appeared to decline as the delay between study and test increased (see Figure 4). The decreasing reminding advantage of analogs over disanalogs as the study-test delay increased may have been due to subjects' memory of the details of individual targets becoming poorer with time. At 5-min and 24-h delays, subjects wrote nearly complete descriptions of targets. However, in the 7-day condition, subjects' descriptions of targets appeared to be less thematically organized and more fragmentary. Hence, the effect of thematic similarity may have decreased as the study-test delay increased because subjects forgot the parts of analog themes that differentiated them from disanalog themes.

In Experiment 1, with remote cues, the proportion of analog reminding and unrelated reminding was approximately equal. In Experiment 2, with remote cues, the frequency of analogical reminding was double that of unrelated reminding ( .34 vs, .19 , respectively). The increase in remote analogical reminding relative to that of unrelated targets is probably due to the more elaborate encoding methods used in Experiment 2-in Experiment 1, subjects merely rated the imageability of targets.

Of the three other experiments in which remote analogical reminding with a 1 -week delay has been examined, two have not shown significant differences between remote analogs and comparison targets (Gentner et al.,

\section{Table 5}

Unrelated Target-Reminding Proportions for Experiment 2 as a Function of Cue Type

\begin{tabular}{|c|c|c|c|c|c|c|}
\hline \multirow[b]{3}{*}{$\begin{array}{l}\text { Situational } \\
\text { Similarity }\end{array}$} & \multicolumn{6}{|c|}{ Cue Type } \\
\hline & \multicolumn{3}{|c|}{ Double Target } & \multicolumn{3}{|c|}{ Unrelated } \\
\hline & $\begin{array}{l}5-\min \\
\text { Delay }\end{array}$ & $\begin{array}{c}24-\mathrm{h} \\
\text { Delay }\end{array}$ & $\begin{array}{l}\text { 7-day } \\
\text { Delay }\end{array}$ & $\begin{array}{l}5 \text {-min } \\
\text { Delay }\end{array}$ & $\begin{array}{l}\text { 24-h } \\
\text { Delay }\end{array}$ & $\begin{array}{l}\text { 7-day } \\
\text { Delay }\end{array}$ \\
\hline Close & .06 & .11 & .08 & .36 & .30 & .32 \\
\hline Remote & .21 & .20 & .17 & .30 & .23 & .29 \\
\hline
\end{tabular}

1993, Experiment 2; Hammond et al., 1991; Gentner et al., Experiment 1, did show an effect). Besides effects caused by the use of different materials, the discrepancy between the results of these studies as compared to those of the present Experiment 2 may be due to the more elaborate encoding methods we used (subjects in the studies of Gentner et al. and Hammond et al. only read the target stories), as well as to our use of a double-target design. Thus, previous failures to find effects of remote analogical reminding with a 1 -week delay are probably attributable to methodological factors.

\section{EXPERIMENT 3}

The results of Experiments 1 and 2 support the hypothesis that remote analogical similarity influences reminding. However, it might be argued that subjects were reminded equally of analog and disanalog targets when given double-target cues, but chose to report analog targets more often than disanalog targets. Such an account might seem implausible given that the instructions in Experiments 1 and 2 encouraged subjects to report all remindings. Nonetheless, the conversational constraint of relevance (Grice, 1989) could have led subjects to edit nonanalogical remindings. If a person states, "I was just reminded of ..." or, "That reminds me of the time we ...," that person is probably following the unspoken rule of not bringing up a reminding unless it is related to the topic of conversation in an interesting fashion. Accordingly, subjects might avoid reporting remindings that are false analogies of (or unrelated to) the reminding cue. If so, the apparent reminding advantage for analog targets over disanalog targets may reflect postaccess selection and mapping rather than retrieval per se.

Such a retrieval-editing account is in fact close to that offered by Falkenhainer, Forbus, and Gentner (1989, pp. 35-39) in their attempt to discount evidence for analogical influences on reminding. These authors suggested that if subjects retrieve more than one episode in memory, each target is mapped to the cue. Only the cue that best maps to the target is kept for further processing and possible overt reporting on a reminding test. Another editing-based variant is that a cue is used iteratively to elicit potential targets. Each activated target is mapped to the cue. If a target is sufficiently analogous to the cue, it is reported. Otherwise the target is suppressed and the retrieval process again iterated (Gentner, 1989; Hammond et al., 1991; Law, Forbus, \& Gentner, 1994).

An important prediction that follows from the retrievalediting account is that analogical similarity will not influence the order in which targets are elicited (because representational structure does not guide the retrieval process), but only whether a target will be reported once it is retrieved. We tested the retrieval-editing hypothesis in Experiment 3 by changing our instructions in one of two between-subjects conditions to discourage subjects from editing their remindings. In the forced condition, subjects were told at retrieval that they should not edit their remindings for any reason. Subjects were also told 
that they should try as hard as they could to be reminded of two targets. (We placed an upper bound on the number of targets to be retrieved because we did not want subjects to attempt to free-recall the entire list.) In the replication condition, subjects were given essentially the same retrieval instructions as in Experiment 2. Both conditions used the same encoding method as was employed in Experiment 2.

If the total number of cues was more than twice the number of targets, subjects would have to be reminded of some targets more than once. Because being forced to report the same target twice could have uninterpretable effects upon subjects' performance, all subjects were given only six cues at retrieval (three close, double-target cues and three remote, double-target cues). Unlike Experiments 1 and 2, subjects were not given additional unrelated cues.

Given that the instructions in the forced condition demanded multiple remindings in response to each cue, the overall reminding frequency of each target type might not provide a sensitive measure of analogical reminding. It is probable that subjects would cue memory multiple times, eventually accessing both the analog and the disanalog target associated with a double-target cue. If analogical similarity guides retrieval, however, analog targets will tend to be retrieved and reported first, followed by disanalog targets. However, if analogical similarity influences only postaccess processes, there is no basis for predicting a difference in order of report between analog and disanalog targets. Accordingly, our principal test of the retrieval-editing hypothesis was based on the frequency of each target type that subjects were reminded of first.

If no analog advantage were obtained for first remindings in the forced condition, evidence would be provided that the effects of thematic similarity found in Experiments 1 and 2 were completely due to retrieval editing. Another possibility is that analogical similarity might influence both initial retrieval and subsequent, postaccess editing. Although an effect of thematic similarity would still be obtained in the forced condition, this effect would be significantly reduced in magnitude relative to that in the replication condition. Finally, an equally strong ana$\log$ advantage for first remindings in the forced condition compared with the replication condition would weaken the retrieval-editing hypothesis.

\section{Method}

Subjects were 56 UCLA undergraduates ( 30 women, 26 men, mean age 19.0 years) and were randomly assigned to either the forced or replication-reminding condition.

Subjects in both conditions were told to write down the stories of which they were reminded, in the order retrieved. Subjects in the forced-reminding condition were given the same instructions as those in the 5-min condition of Experiment 2 but were also told,

Write down the first two stories that you are reminded of from the stories you rated earlier. Please do not exclude or omit any stories that you happen to be reminded of, for any reason-write down every story that comes to mind. For each story in the booklet in front of you, you should be able to be reminded of two of the previous stories you rated. Please try to think as hard as you can until you are reminded of two stories. However, it is possible that some stories may not remind you of two (or even one) of the previous stories even though you are trying hard. If this occurs, please go on to the next story in the packet.

The final reminding phase took approximately 12 and $20 \mathrm{~min}$ to complete, respectively, in the replication condition and in the forced condition.

\section{Results}

Overall, the results show no support for the retrievalediting hypothesis. However, there is evidence that subjects in the replication condition edited remindings of unrelated targets. Mean retrieval differences between conditions were tested in a 2 (thematic similarity: analog target, disanalog target) $\times 2$ (situational similarity: close cue, remote cue) $\times 2$ (reminding instructions: forced, replication) mixed-subjects/within-stories min $F^{\prime}$ ANOVA. Frequencies for all remindings of analog targets and disanalog targets are presented in Figure 5.

Subjects in the forced condition were reminded of more stories than were subjects in the replication condition. Both the interaction of reminding instructions with thematic similarity and the main effect of reminding instructions were reliable respectively $\left[\min F^{\prime}(1,80)=10.52, p<.01\right.$, $\left.\min F^{\prime}(1,80)=12.74, p<.001\right]$. Also, given the forcedcondition instructions, subjects accessed both the analog and the disanalog in $56 \%$ of retrievals with close cues and in $43 \%$ of retrievals with remote cues. In contrast, in the replication condition, subjects accessed both the ana$\log$ and the disanalog in $8 \%$ of retrievals with close cues and in $2 \%$ of retrievals with remote cues.

Despite the overall increase in the number of targets reported in the forced condition relative to the replication condition, the qualitative influences of both thematic similarity and situational similarity on overall reminding frequencies were remarkably similar to those observed in the double-target conditions of Experiments 1 and 2 . Across both conditions, subjects were reminded of more analogs than disanalogs $\left[\mathrm{min} F^{\prime}(1,53)=5.97, p<.05\right]$.

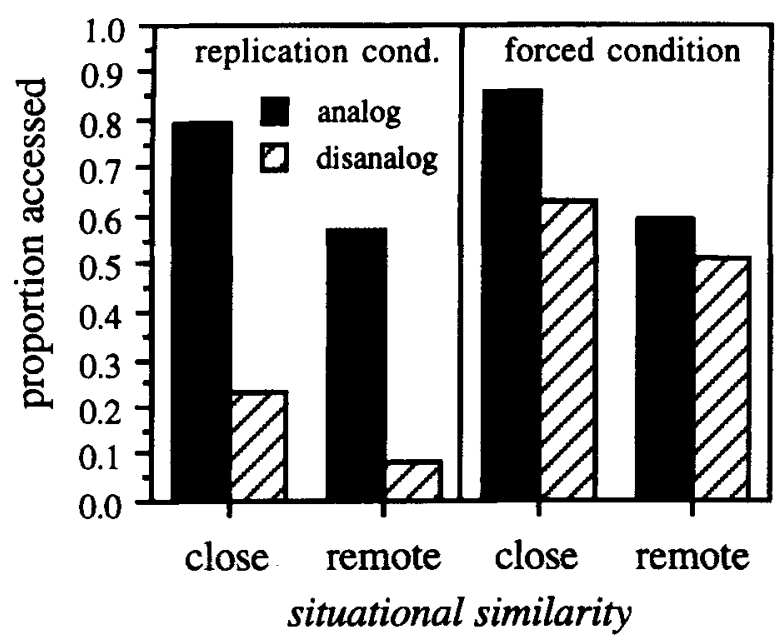

Figure 5. Overall reminding for target stories in Experiment 3. 
Planned comparisons in the forced condition revealed that the effect of thematic similarity was significant by min $F^{\prime}$ analysis in the close condition $\left[\min F^{\prime}(1,53)=5.56\right.$, $p<.05]$, and was significant by subject ANOVA and by story ANOVA in the remote condition $\left[F_{1}(1,27)=4.30\right.$, $F_{2}(1,27)=4.72$, both $\left.p s<.05\right]$.

Our primary test of the retrieval-editing hypothesis is based on the frequencies of first remindings. These are presented in Figure 6 . As can be seen by comparing first remindings for the replication condition (left panel) and the forced condition (right panel), the results show no support for the retrieval-editing hypothesis. There was no difference in the number of stories accessed by subjects as a function of reminding instructions $\left(\min F^{\prime}<1\right)$, and none of the following comparisons were reliable: retrieval instruction $\times$ thematic similarity $\left[\min F^{\prime}(1,76)=\right.$ 1.07, n.s.]; situational similarity $\times$ thematic similarity $\left[\min F^{\prime}(1,78)=2.30\right.$, n.s.]; retrieval instruction $\times$ situational similarity $\left(\min F^{\prime}<1\right)$; and retrieval instruction $\times$ thematic similarity $\times$ situational similarity $\left(\min F^{\prime}<1\right)$.

Collapsing across the two instructional conditions, subjects were more frequently reminded of analog targets than of disanalog targets [ $\left.\min F^{\prime}(1,76)=32.19, p<.0001\right]$. Planned comparisons indicated that subjects were more frequently reminded of analogs than of disanalogs, given close cues $\left[\min F^{\prime}(1,76)=29.30, p<.0001\right]$, and given remote cues $\left[\min F^{\prime}(1,78)=15.30, p<.0001\right]$. The effect of thematic similarity in the forced condition was reliable for both remote and close cues, respectively [min $\left.F^{\prime}(1,45)=5.10, p<.05 ; \min F^{\prime}(1,52)=9.28, p<.01\right]$. Additionally, subjects' first remindings were influenced by situational similarity (close $>$ remote) $\left[\min F^{\prime}(1,67)=\right.$ $19.27, p<.0001]$.

The proportions of unrelated target remindings are shown in Table 6 . The results appear to show that subjects edited unrelated remindings. Subjects in the forced condition reported approximately twice as many unrelated first remindings as did those in the replication condition. When all first remindings of analog, disanalog, and

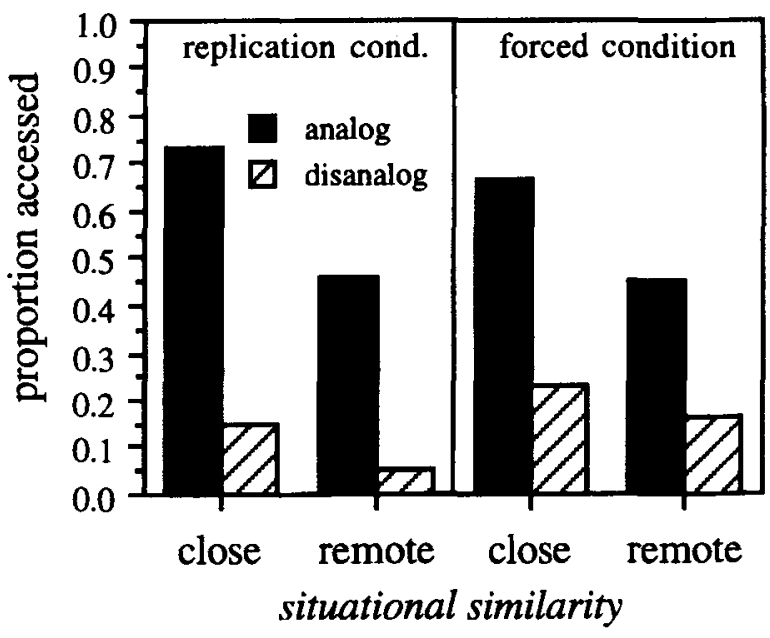

Figure 6. First-remindings for target stories in Experiment 3. unrelated targets were analyzed, a main effect of reminding instructions was found (forced $>$ replication) [min $\left.F^{\prime}(1,70)=6.29, p<.025\right]$. However, the reminding instructions $\times$ thematic similarity interaction was not reliable $\left(\min F^{\prime}<1\right)$. The difference in unrelated reminding between the replication condition and the forced condition was not reliable by $\min F^{\prime}$ analysis but was marginally significant by subject ANOVA and significant by story ANOVA $\left[F_{1}(1,54)=3.84, p<.10 ; F_{2}(1,27)=4.75\right.$, $p<.05]$.

\section{Discussion}

The most important result obtained in Experiment 3 is the absence of any significant difference between the forced condition and the replication condition with respect to first remindings of analogs and disanalogs. The lack of any such difference is not attributable to ineffective instructions; compared with subjects in the replication condition, subjects in the forced-reminding condition were reminded of more targets overall.

Compared with subjects in the replication condition, subjects in the forced condition appear to have had more first remindings of unrelated targets. A plausible conclusion is that subjects in the replication condition edited unrelated remindings but did not edit analog remindings and disanalog remindings. Even so, Experiment 3 provides no support for the hypothesis that the analog reminding advantages obtained in Experiments 1 and 2 were due to subjects completely or partially editing their remindings of disanalog targets.

\section{GENERAL DISCUSSION}

\section{Overview of Results}

The present results provide compelling empirical evidence that remote analogical similarity guides human memory retrieval. In Experiments 1-3, subjects were more often reminded of remote analogs than of remote disanalogs. As demonstrated in Experiment 2, this difference was obtained even with a 1-week delay. Additionally, the results of Experiments 1-3 consistently demonstrated the role of schematic knowledge for social and physical situations in reminding. Across all experiments, reminding of close analogs and disanalogs was approximately twice that of remote analogs and disanalogs.

The results of Experiment 3 argue against the possibility that subjects were using a "retrieve-and-match" strategy in which targets were randomly free-recalled and then matched to the cue (Falkenhainer et al., 1989; Gentner, 1983, 1989; Hammond et al., 1991). Subjects in the forced-reminding condition of Experiment 3 were told to report the first story that came to mind, as well as to try to be reminded of two targets. If subjects had been randomly recalling targets, the advantage of analog stories relative to disanalog stories should have been significantly less in the forced condition than in the replication condition. However, the pattern of subjects' first remindings of analogs and disanalogs in the forced condition was no different than that observed for subjects 
Table 6

Unrelated Target Retrieval Proportions in Experiment 3 for All and First Remindings as a Function of Retrieval Instructions

\begin{tabular}{lccccc}
\hline \multirow{2}{*}{$\begin{array}{l}\text { Situational } \\
\text { Similarity }\end{array}$} & \multicolumn{2}{c}{ All Reminding } & & \multicolumn{2}{c}{ First Reminding } \\
\cline { 2 - 3 } \cline { 6 - 6 } & Rep. & Forced & & Rep. & Forced \\
\hline Close & .06 & .29 & & .06 & .10 \\
Remote & .25 & .54 & .15 & .30 \\
\hline
\end{tabular}

Note-Rep., replication condition.

given the less coercive instructions in the replication condition.

\section{Generalization to Memory Retrieval in Other Situations}

In the present experiments we explored directed reminding rather than spontaneous reminding. The question of whether directed reminding and spontaneous reminding are produced by the same basic processing mechanisms awaits further study. However, the results of Wharton and Lange (1994, Experiment 1) suggest that remote analogical similarity can influence retrieval even if subjects are not directed to retrieve prior episodes from memory. Subjects in that study initially summarized the common plot of pairs of analogous stories. Later, subjects rated the comprehensibility of new stories that were remote analogs or remote disanalogs of the summarized pairs. Results from a debriefing questionnaire indicated that subjects, while making the comprehensibility ratings, were more frequently reminded of analogs than of disanalogs (but see Seifert, McKoon, Abelson, \& Ratcliff, 1986).

It is important to note that our findings should not be expected to simply and directly apply to other situations involving reminding. Generalizing from our results (especially to analogical problem solving) should be done with awareness of the procedures we used, the expertise of our subjects, and the high level of nonanalog reminding.

One reason for the relatively high levels of remote analogical reminding observed in the present experiments is that our experimental procedure took advantage of transferappropriate processing (i.e., retrieval is positively correlated with the similarity of encoding and retrieval operations to each other). To illustrate, Needham and Begg (1991) found that subjects who first tried to solve a source problem before being told its solution had a higher solution rate on a transfer problem than did subjects who studied the same source problem for later recall. The two experiments in which we obtained the largest effects of remote analogical reminding (Experiments 2 and 3 ) both used an encoding procedure, cued recall, that was similar to the retrieval procedure, directed reminding.

Another factor to be aware of when generalizing from the present experiments is the relative expertise of our subjects in the domain described by our materials-everyday social and personal themes. It is generally accepted that the more one knows about a domain, the more likely it is that underlying causal relations (e.g., goals, plans, themes) will be recognized (Chi, Feltovich, \&
Glaser, 1981; Novick, 1988; Novick \& Holyoak, 1991). Our similarity ratings and reminding results indicate that subjects recognized and understood the causal relations that were only implied in the cues and targets. We probably would have obtained no effect of remote analogical reminding had we tested the same subject pool with examples instantiating themes drawn from physics or law (domains in which our subjects would be novices). Thus, the results of the present experiments do not generalize well to memory retrieval or analogical problem solving in unfamiliar domains.

Finally, the implications of the high level of nonana$\log$ reminding produced with remote cues should be noted. Across Experiments 1-3, the combined level of reminding of unrelated targets and disanalog targets given remote cues was approximately equal to that of analog targets. The ratio of unrelated reminding and disanalog reminding to analog reminding would likely have been much higher if there were more object similarities and more situational similarities between cues and nonanalogous targets. To speculate, subjects' low spontaneous solution rate in studies such as that of Gick and Holyoak (1980) could have been due to reminding interference from other items in memory as much as to a lack of sensitivity to remote analogical similarity. Direct empirical investigation of the role of retrieval interference in analogical reminding is needed.

Our findings do imply that memory retrieval is influenced by remote analogical similarity. However, the extent to which remote analogical reminding will take place in a given situation will be a function of factors such as transfer-appropriate processing, domain expertise, and reminding interference. Further development of theories of analogical reminding would be aided by models that quantified the effect of these additional, relevant variables.

\section{Analogical Similarity and Memory Models}

The sensitivity of human memory retrieval to analogical similarity appears to lie outside the range of phenomena accounted for by most memory models proposed in the last two decades (see, e.g., Eich, 1982; Hintzman, 1986; Murdoch, 1982; McClelland \& Rumelhart, 1985; Raaijmakers \& Shiffrin, 1981). Most of these models represent both memory probes and items in memory as unstructured vectors of microfeatures. Although such models are simple and intuitively appealing, unstructured onedimensional vectors are unable to provide effective representations of role bindings - assignments of elements to meaningful roles in hierarchical representations (Barnden, 1994; Fodor \& McLaughlin, 1990; Fodor \& Pylyshyn, 1988). The ability to recognize consistent correspondences between two hierarchical representations is at the core of what constitutes an analogy. Consequently, the basic representational conventions of feature-list models are inadequate to account for the present findings in both remote and close conditions.

The role of remote analogical similarity in retrieval has been addressed by several memory models that apply to reminding in general (not just as it occurs in problem solv- 
ing or case-based reasoning). Models such as ARCS (Thagard, Holyoak, Nelson, \& Gochfeld, 1990), MAC/FAC (Forbus, Gentner, \& Law, 1995), and REMIND (Lange \& Wharton, 1994) use structure-sensitive representations and retrieval operations and so are compatible with the notion of remote analogical reminding. However, ARCS and MAC/FAC retrieve only targets from memory that share explicit semantic similarity with the cue. (In these models, semantic similarity can be at any level of similarity, including that of themes.) The representations used for encoding and retrieval in the present experiments required extensive elaboration by subjects because neither remote analogs nor close analogs shared any explicit surface overlap. At the least, our results imply that memory models have to be integrated with theories of discourse comprehension in order to account for the construction of cue representations and target representations (see Lange \& Wharton, 1994, for an integrated comprehension-reminding model).

In conclusion, our results show that remote analogical similarity influences memory. However, the ability to predict the influence of remote analogical similarity in a given situation awaits more developed models of reminding and of analogical problem solving. Nonetheless, the positive aspects of our findings deserve emphasis. Our experiments consistently demonstrated that even with no pragmatic reason to do so, people will retrieve remote analogs from memory. Human memory appears suited for reminding of problem solutions and insights, as well as for recall of facts and dates.

\section{REFERENCES}

Aввот, V., BLACK, J. B., \& SMith, E. E. (1985). The representation of scripts in memory. Journal of Memory \& Language, 24, 179-199.

BARNDEN, J. A. (1994). On the connectionist implementation of analogy and working memory matching. In J. A. Barnden \& K. J. Holyoak (Eds.), Advances in connectionist and neural computation theory: Vol. 3. Analogy, metaphor, and reminding (pp. 327-374). Norwood, NJ: Ablex.

Bellezza, F. S., \& Ноyт, S. K. (1992). The self-reference effect and mental cueing. Social Cognition, 10, 51-78.

BJork, R. A., \& Bjork, E. L. (1992). A new theory of disuse and an old theory of stimulus fluctuation. In A. F. Healy, S. M. Kosslyn, \& R. M Shiffrin (Eds.), Essays in honor of William K. Estes (Vol. 2, pp. 35-67). Hillsdale, NJ: Erlbaum.

Cantor, N., Mischel, W., \& Schwartz, J. C. (1982). A prototype analysis of psychological situations. Cognitive Psychology, 14, 45-77.

Chi, M. T. H., Feltovich, P. J., \& Glaser, R. (1981). Categorization and representation of physics problems by experts and novices. $C o g$ nitive Science, 5, 121-152.

Clark, H. H. (1973). The language-as-fixed-effect fallacy: A critique of language statistics in psychological research. Journal of Verbal Learning \& Verbal Behavior, 12, 335-359.

Clement, J. (1988). Observed methods for generating analogies in scientific problem solving. Cognitive Science, 12, 563-586.

Clement, J. (1991). Nonformal reasoning in experts and in science students: The use of analogies, extreme cases, and physical intuition. In J. F. Voss, D. N. Perkins, \& J. W. Segal (Eds.), Informal reasoning and education (pp. 345-362). Hillsdale, NJ: Erlbaum.

DunBaR, K. (1995). How scientists really reason: Scientific reasoning in real-world laboratories. In R. J. Sternberg \& J. E. Davidson (Eds.), The nature of insight (pp. 365-395). Cambridge, MA: MIT Press. DYER, M. G. (1983). In-depth understanding: A computer model of in- tegrated processing for narrative comprehension. Cambridge, MA: MIT Press.

EICH, J. M. (1982). A composite holographic associative recall model. Psychological Review, 89, 627-661.

Fal KENHAINER, B., ForBus, K. D., \& GENTNER, D. (1989). The structure-mapping engine: Algorithm and examples. Artificial Intelligence, 41, 1-63.

Fodor, J. A., \& McLaughlin, B. P. (1990). Connectionism and the problem of systematicity: Why Smolensky's solution doesn't work. Cognition, 35, 183-204.

Fodor, J. A., \& Pylyshyn, Z. W. (1988). Connectionism and cognitive architecture: A critical analysis. In S. Pinker \& J. Mehler (Eds.), Connections and symbols (pp. 3-71). Cambridge, MA: MIT Press.

Forbus, K. D., GenTNER, D., \& LAW, K. (1995). MAC/FAC: A model of similarity-based retrieval. Cognitive Science, 19, 144-205.

GENTNER, D. (1983). Structure-mapping: A theoretical framework. Cognitive Science, 7, 155-170.

GENTNER, D. (1989). The mechanisms of analogical learning. In S. Vosniadou \& A. Ortony (Eds.), Similarity and analogical reasoning (pp. 199-241). New York: Cambridge University Press.

Gentner, D., Rattermann, M., \& Forbus, K. (1993). The roles of similarity in transfer: Separating retrievability from inferential soundness. Cognitive Psychology, 25, 524-575.

GICK, M. L., \& HolyOAK, K. J. (1980). Analogical problem solving. Cognitive Psychology, 12, 306-355.

Gick, M. L., \& Paterson, K. (1992). Do contrasting examples facilitate schema acquisition and analogical transfer? Canadian Journal of Psychology, 46, 539-550.

Gillund, G., \& Shiffrin, R. M. (1984). A retrieval model for both recognition and recall. Psychological Review, 91, 1-67.

Graesser, A. C., Singer, M., \& Trabasso, T. (1994). Constructing inferences during narrative text comprehension. Psychological Review, $101,371-395$.

Grice, H. P. (1989). Studies in the way of words. Cambridge, MA: Harvard University Press.

HALFORD, G. S. (1992). Analogical reasoning and conceptual complexity in cognitive development. Human Development, 35, 193-217.

HALFORD, G. S., \& WILSON, W. H. (1980). A category theory approach to cognitive development. Cognitive Psychology, 12, 356-411.

HAMmOND, K. J. (1989). Case-based planning: Viewing planning as a memory task. Boston: Academic Press.

Hammond, K. J., Seifert, C. M., \& Gray, K. C. (1991). Functionality in analogical transfer: A hard match is good to find. Journal of the Learning Sciences, 1, 111-152.

HintZMAN, D. L. (1986). "Schema abstraction" in a multiple-trace memory model. Psychological Review, 93, 411-428.

HOLYOAK, K. J., \& KOH, K. (1987). Surface and structural similarity in analogical transfer. Memory \& Cognition, 15, 332-340.

Holyoak, K. J., \& ThaGaRd, P. (1989). Analogical mapping by constraint satisfaction. Cognitive Science, 13, 295-355.

Holyoak, K. J., \& ThaGard, P. (1995). Mental leaps: Analogy in creative thought. Cambridge, MA: MIT Press.

Johnson, H. M., \& SEIFERT, C. M. (1992). The role of predictive features in retrieving analogical cases. Journal of Memory \& Language, 31, 648-667.

KEANE, M. (1985). On drawing analogies when solving problems: A theory and test of solution generation in an analogical problem-solving task. British Journal of Psychology, 76, 449-458.

Kolodner, J. L. (1993). Case-based reasoning. San Mateo, CA: Morgan Kaufmann.

LANGE, T., \& Wharton, C. (1994). Remind: Retrieval from Episodic Memory by INferencing and Disambiguation. In J. A. Barnden \& K. J. Holyoak (Eds.), Advances in connectionist and neural computation theory: Vol. 3. Analogy, metaphor, and reminding (pp. 29-94). Norwood, NJ: Ablex.

LAW, K., Forbus, K. D., \& GentNER, D. (1994). Simulating similaritybased retrieval: A comparison of ARCS and MAC/FAC. In A. Ram \& K. Eiselt (Eds.), Proceedings of the 16th Annual Conference of the Cognitive Science Society (pp. 543-548). Hillsdale, NJ: Erlbaum.

McClelland, J. L., \& RumelharT, D. E. (1985). Distributed memory and the representation of general and specific information. Journal of Experimental Psychology: General, 114, 159-188. 
Murdock, B. B., JR. (1982). A theory for the storage and retrieval of item and associative information. Psychological Review, 89, 609-626.

Needham, D. R., \& BegG, I. M. (1991). Problem-oriented training promotes spontaneous analogical transfer: Memory-oriented training promotes memory for training. Memory \& Cognition, 19, 543-557.

Novick, L. N. (1988). Analogical transfer, problem similarity, and expertise. Journal of Experimental Psychology: Learning, Memory, \& Cognition, 14, 510-520.

Novick, L. R., \& Holyoak, K. J. (1991). Mathematical problem solving by analogy. Journal of Experimental Psychology: Learning, Memory, \& Cognition, 17, 398-415.

PERKINS, D. N. (1983). Novel remote analogies seldom contribute to discovery. Journal of Creative Behavior, 17, 223-239.

Poze, T. (1983). Analogical connections-The essence of creativity Journal of Creative Behavior, 17, 240-258.

PrEMack, D. (1983). The codes of man and beasts. Behavioral $\&$ Brain Sciences, 6, 125-167.

RaAijmakers, J. G. W., \& Shiffrin, R. M. (1981). Search of associative memory. Psychological Review, 88, 93-134.

RattermanN, M. J., \& Gentner, D. (1987). Analogy and similarity Determinants of accessibility and inferential soundness. In Proceedings of the Ninth Annual Meeting of the Cognitive Science Society (pp. 22-34). Hillsdale, NJ: Erlbaum.

READ, S. J., \& CESA, I. L. (1991), This reminds me of the time when ... Expectation failures in reminding and explanation. Journal of Experimental Social Psychology, 27, 1-25.

Read, S. J., Druian, P. R., \& Miller, L. C. (1989). The role of causal sequence in the meaning of actions. British Journal of Social Psychology, 28, 341-351.

ReEves, L. M., \& WeIsBerG, R. W. (1994). The role of content and abstract information in analogical transfer. Psychological Bulletin, 115 $381-400$.

RIFKIN, A. (1985). Evidence for a basic level in event taxonomies Memory \& Cognition, 13, 538-556.

SCHANk, R. C. (1982). Dynamic memory. New York: Cambridge University Press.

Seifert, C. M., McKoon, G., Abelson, R. P., \& Ratcliff, R. (1986). Memory connections between thematically similar episodes. Journal of Experimental Psychology: Learning, Memory, \& Cognition, 12. 220-23I.

Thagard, P., Holyoak, K. J., Nelson, G., \& Gochfeld, D. (1990). Analog retrieval by constraint satisfaction. Artificial Intelligence, $\mathbf{4 6}$ 259-310

WeIsBerg, R. W. (1993). Creativity: Beyond the myth of genius, New York: W. H. Freeman.

Wharton, C. M., Holyoak, K. M., Downing, P. R., Lange, T. E. Wickens, T. D., \& MELz, E. R. (1994). Below the surface: Analogi- cal similarity and retrieval competition in reminding. Cognitive Psychology, 26, 64-101.

Wharton, C. M., \& Lange, T. E. (1994). Analogical transfer through comprehension and priming. In A. Ram \& K. Eiselt (Eds.), Proceedings of the I6th Annual Conference of the Cognitive Science Society (pp. 934-939). Hillsdale, NJ: Erlbaum.

WiCKENS, T. D., \& KEPPEL, G. (1983). On the choice of design and of test statistic in the analysis of experiments with sampled materials. Journal of Verbal Learning \& Verbal Behavior, 22, 296-309.

\section{NOTES}

1. Remote analogical reminding is equivalent to what has been termed cross-contextual analogical reminding in the case-based reasoning literature (Schank, 1982). We avoid the latter term here to prevent confusion with the well-established meaning of "context" in psychology as referring to extra-stimulus factors, suchas physical location and time of day.

2. There are differing interpretations about what constitutes an appropriate comparison for reminding of analogs. Johnson and Seifert (1992) focused on whether reminding is sensitive to partial plan-goal overlap, rather than to analogical similarity per se. Although their study provides evidence consistent with remote analogical reminding, this evidence is based on comparisons between the retrieval of analogous and unrelated targets rather than between analogous and partially related targets. The analog-unrelated retrieval comparison is a less strict criterion than has been used in other direct reminding studies.

3. Wharton et al. (1994) referred to single-target and double-target designs, respectively, as singleton and competition designs. The names of these designs have been changed to avoid associations to possible retrieval mechanisms (e.g., retrieval competition).

4. In the double-target condition, some subjects might have been reminded of the analog target while encoding the disanalog target (or vice versa). However, it is uncertain how this could influence retrieval. The theme of the target analog could be made clearer by comparison with a disanalog, thus strengthening the analogical reminding effect (see, e.g., Gick \& Paterson, 1992). Even so, memory retrieval would still be driven by analogical similarity. It is also possible that being reminded of the first target while encoding the second target would create an episodic association between the two because descriptions of both targets would be in short-term memory at the same time (see Gillund \& Shiffrin, 1984). This episodic association should lead to the other target being accessed if either target were first retrieved. If one assumes that the initial reminding frequency of analogs will be higher than that of disanalogs, this episodic association should lead to a relatively increased level of disanalog reminding. Accordingly, the effect of analogical similarity would decrease. 


\begin{abstract}
APPENDIX
This Appendix includes two sets of six stories each. The first set is derived from materials used by Seifert et al. (1986), the second from Rattermann and Gentner (1987). Each set's arrangement is identical to that of Table 1.
\end{abstract}

Theme 1: Taking appropriate action too late (i.e., closing the barn door after the horse has gotten out)

Target: Phil was in love with his secretary. However, he was afraid of responsibility, so he kept dating others and made up excuses to postpone the wedding. Finally, his secretary got fed up, began dating, and fell in love with a doctor. When Phil found out, he went to her and proposed marriage, showing her the ring he had bought. His secretary was already planning her honeymoon with the doctor by that time.

Close Cue: Dr. Popoff depended on his graduate student, Sandy. However, he kept finding reasons not to upgrade his research facilities because he was very cheap. After many fruitless meetings, Sandy began inquiring around and was accepted to work at a corporate laboratory. Dr. Popoff hurriedly offered Sandy lots of new research equipment when he heard the rumors. But by now, Sandy was deciding how she was going to set up things at the corporate laboratory.

Remote Cue: Oscar the tiger had the greatest house in the best part of the forest. He believed that his luck was so good that a big storm would never come to the area that he lived in. A neighboring raccoon, Arnie, kept telling Oscar that his roof was broken in places and would never protect the rest of the house during storm season. However, Oscar was taken with himself, and tried to convince Arnie that nothing was wrong with his roof. One morning, a giant storm appeared in the distance. Oscar panicked and decided that Arnie was right. Oscar went off and got all of the materials he would need. By the time he was ready to start, the rain was coming down so hard that Oscar couldn't work anymore. Oscar's roof collapsed and the inside of his house was ruined.
Theme 2: Reconciliation and learning from experience

Target: Larry was infatuated with Wendy. Wendy got frustrated, began going out, and became close to a football player. Unfortunately, the football player didn't want to be tied down, so he started seeing other girls, and made up reasons why he didn't want to see her regularly. Larry heard about this, brought her flowers, and asked if she would go to the prom with him. On her own, Wendy had been hoping he would ask her.

Close Cue: After several confrontations with the publisher of the magazine, Denise Benson, Evan sent his portfolio around. Denise thought that Evan was the best graphic designer they employed. Evan decided to work at a competing magazine. However, the competing magazine never rewarded good workers because it didn't believe in giving bonuses. Denise immediately proposed giving Evan a substantial raise when she realized what was occurring. Around then, he was wondering if she would welcome him back.

Remote Cue: Denise, a beaver, loved her dam. However, she hadn't used very strong branches before because she was inexperienced. A very heavy winter snow caused the river to rise in the spring and her dam was washed away. Denise wanted to fix the dam but couldn't because river waters stayed so high. Finally in the middle of the summer, the river came down. Denise started to build the dam stronger and better than she had before. 
APPENDIX (Continued)

Theme 1: Betrayal of a deal

Target: Once there was a hawk named Karla. She saw a sportsman armed with a longbow coming after her. Karla noticed that some of the arrows had no feathers. She thought that she might be able to strike a deal. Karla flew down and donated a few of her tail feathers to the sportsman. The sportsman promised never to attack hawks again. One day she was nesting on a rocky cliff when the sportsman shot at her. The arrows now had her tail feathers on them.

Close Cue: Karnor was a small country. One day Karnor realized that its warlike neighbor, Gagrach, was arming against them. The Karnorians realized that all of the Gagrach missiles were badly made and decided that an alliance could be formed. The Karnor ambassador gave a lot of missile components to the Gagrach military. Gagrach indicated that they would never make war on Karnor after this. However, the Gagrach declared war on them during a holiday, while the Karnorians were feasting. The rockets were now constructed with reliable Karnorian components.

Remote Cue: June realized that her classmate Don didn't like her. June decided to do something nice for Don so that he wouldn't gossip about her. Don was an artist and was taking a drawing course. June agreed to pose for him in a bathing suit at the beach, and so Don seemed as if he now liked her. Later, at the school library, Don showed some paintings. One of them was an unflattering nude that was based on the beach drawing. The painting was obviously recognizable as June.
Theme 2: Making a deal to avoid a bad situation

Target: One day, lying on a big boulder, was a snake called Elrod. He saw a hunter coming with a blow gun tracking him. The hunter fired. Elrod realized that the darts had no poison and so he realized that he might be able to make a trade. He crawled over and gave some poison to the hunter so that the darts now had his poison on them. The hunter agreed never to kill snakes again.

Close Cue: Once there was a small kingdom, Gosnia. One day, Utica, an imperialistic empire, boasted that they would take Gosnia. When the Utica had put its fleet out to sea, Gosnia found out that all of the Utica ships were slow. Gosnia believed that an alliance could be formed. The Gosnian king showed the Uticans how to build their boats with advanced Gosnian technology. The Uticans said that from now on they would never invade Gosnia.

Remote Cue: June and another girl, Dana, were both rivals for Joe. June realized that Dana wasn't very aware of style and so she showed her some fashion photographs in magazines and took her shopping. Dana now looked very cute and chic. Dana was so grateful that she told June that she would stop flirting with Joe. 